\title{
Adventures and lessons of an American biochemist in China
}

\author{
Christopher J. Vavricka ${ }^{\bowtie}$ \\ CAS Key Laboratory of Pathogenic Microbiology and Immunology, Institute of Microbiology, Chinese Academy of Sciences, \\ Beijing 100101, China \\ $\bowtie$ Correspondence: chris@im.ac.cn, cjv@vt.edu
}

It's very interesting how events often lead up to each other seemingly by chance, but appear almost perfectly planned out when looking back. For the past two years, I have worked as an International Young Scientist Research Fellow at the Institute of Microbiology, Chinese Academy of Sciences in Beijing, China. Many people ask me, especially Chinese graduate students, why an American would choose to come to China as a postdoctoral researcher. I think that a strong curiosity to explore something new should be a fundamental quality of any successful scientist. In 2005, when I decided to stay at Virginia Tech (Virginia Polytechnic Institute and State University) to pursue my PhD studies in biochemistry, I was actually warned by many of my colleagues about continuing my research in the same university as my undergraduate studies. At that time, I did not take this very seriously; however, after spending the last two years working as a postdoc in China, I think I can now really appreciate this advice. Although I would never have ended up where I am now if I did not stay at Virginia Tech and I am truly grateful for the experience and knowledge I gained from my graduate studies in biochemistry, I really think that the mind-opening experience of moving to China has helped me become a much better scientist.

Perhaps it was my fascination with Traditional Chinese Medicine and Chinese Gongfu that originally sparked my interest in coming here. China is one of the oldest surviving civilizations and cultures in the world with a continuous history of over 4000 years and for a majority of world history has been at the forefront of technology and society. Although China has faced many challenges over the past 100-200 years, today China has enormous potential for growth and development and some people even compare China to America as it was 100 years ago during a time of great development and advancement. Even Napolean Bonaparte is quoted as saying, "Let China sleep, for when China wakes, the world will shake." In terms of scientific research output, China is

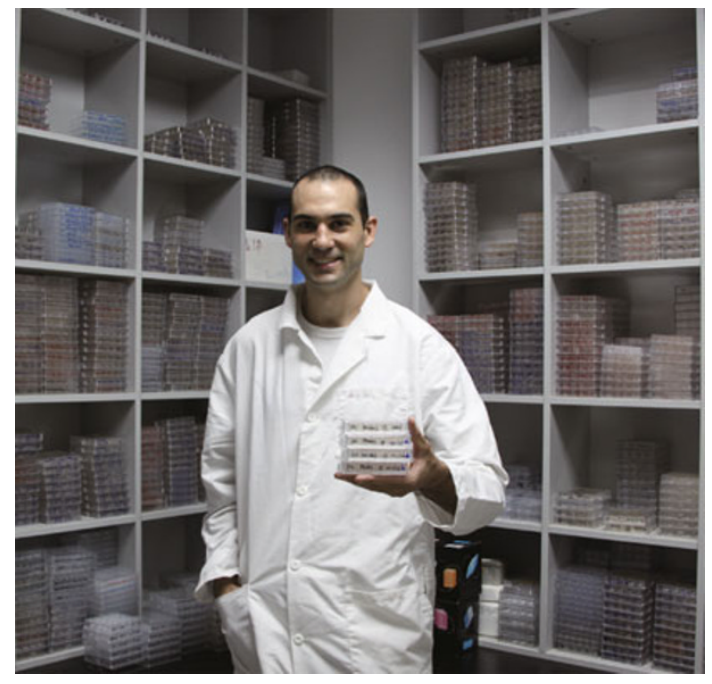

Chris holding some crystal screening plates for influenza neuraminidase in one of the protein crystal storage areas at the Institute of Microbiology, Chinese Academy of Sciences, Beijing, China.

projected to overtake the United States in total number of scientific publications by 2013. Additionally, today many foreign experts are being recruited to China and many skilled Chinese scientists from top research institutes across the world are returning home to carry out their research in Chinese institutes.

I had been interested in coming to China for many years before completing my graduate studies. Actually, I even seriously considered formally studying Traditional Chinese Medicine or taking an English teaching job in China instead of pursuing graduate studies in biochemistry. Although I chose my graduate lab rotations in the Virginia Tech Center for Genomics with Dr. Rich Helm and Dr. Malcolm Potts, and with 


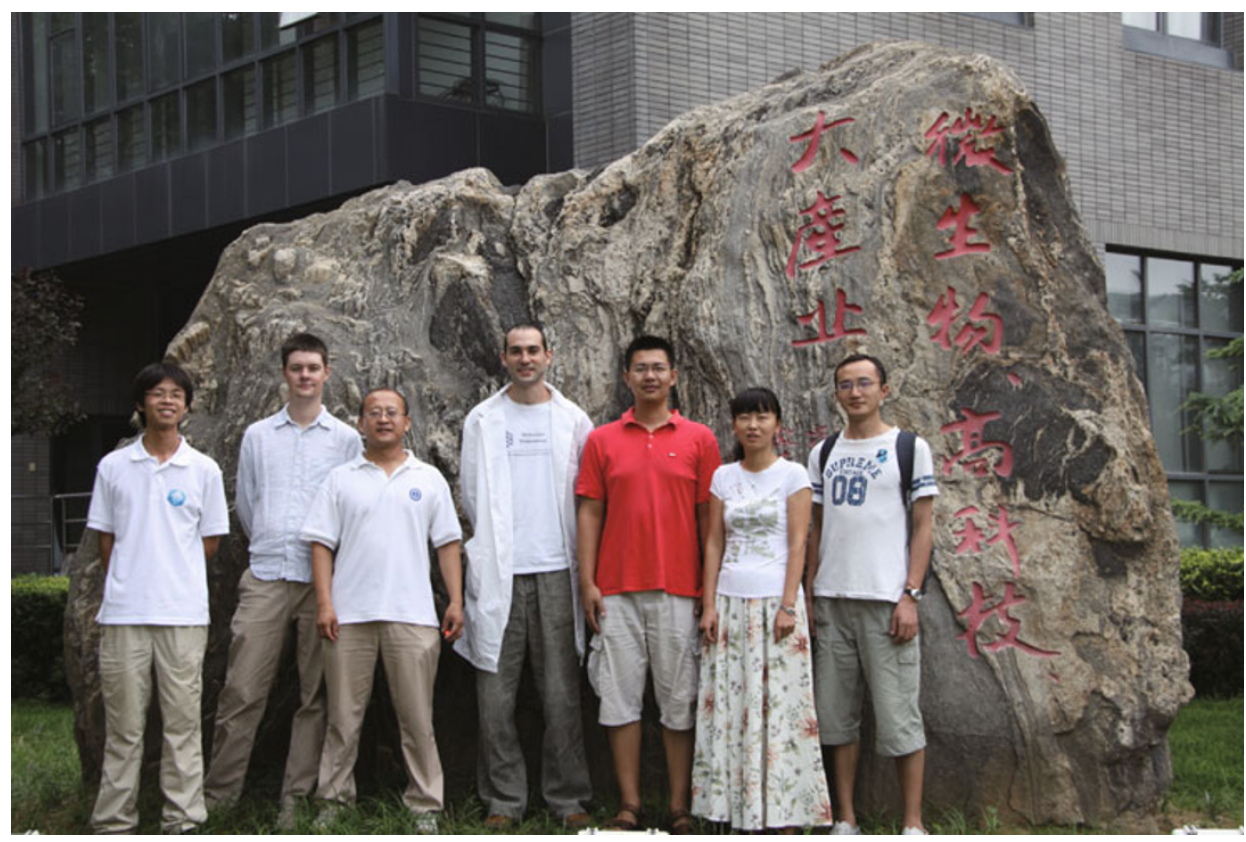

Chris with some lab members of the George Fu Gao lab in front of the Institute of Microbiology, Chinese Academy of Sciences, Beijing, China.

Dr. Glenda Gillaspie's plant signaling research lab, at the end of my second rotation I decided to do my dissertation research in the field of protein biochemistry with Professor Jianyong Li, a scientist originally from Beijing, China. My choice to work with Professor Li was based primarily on our common interest in enzymes involved in aromatic amino acid metabolism (Vavricka et al., 2010a, 2010b, 2011a); however the possibility to find an exchange program or future position in China was also a consideration for me. Professor Li and another Senior Research Scientist in our lab, Dr. Han Qian, both of whom had worked as veterinary research scientists at China Agricultural University in Beijing, introduced me to my current advisor, Professor George Fu Gao, who is a colleague of theirs from China Agricultural University.

Professor Gao's research lab also has a focus on protein structure and function and after completing my PhD dissertation I decided to come to his lab as a postdoc. I really had no idea what to expect so I did my best to arrive with a positive attitude and an open mind. After spending my entire life in the US and the past 9 years in the small town of Blacksburg, Virginia, living and working in Beijing really presented a completely different environment to adapt and grow in. Even everyday life and simple language became a difficult task and figuring out how things worked in my new lab also took a lot of effort to adjust to. I had to learn so many new things that I was forced to keep an open mind and adapt or become helpless. As scientists who become experts in our fields of research, there is a real danger of losing the creative attitude necessary to be open to novel ideas that can push the boundaries of the established understanding. When approaching a new scientific problem or debating some research ideas with colleagues or even reviewers, I always try to stay open minded and flexible to learn as much as I can. Many top Chinese scientists spend time studying abroad in research institutes all over the world, and perhaps this is an experience that we have in common.

Although coming from an American biochemistry lab and adjusting to a Chinese lab can be very frustrating in many aspects, the last two years have been extremely productive. I have been heavily involved in studies that provide insight into the function and inhibition of the influenza neuraminidase, which is currently the major drug target against seasonal and pandemic flu. Through my participation in the influenza neuraminidase research group in Professor George $\mathrm{Fu}$ Gao's lab, I have been published in many quality science journals (Li et al., 2010; Liu et al., 2010; Vavricka et al., 2011b, 2011c; Wang et al., 2011). I have also been given the pleasure of presenting this work at the $24^{\text {th }}$ International Conference on Antiviral Research in Sofia Bulgaria, the 2011 American Crystallographic Association Meeting in New Orleans as well as a few China-Japan joint virology meetings. Furthermore, I have had the pleasure of collaborating with many top scientists from China, Japan, United States, Canada and Australia.

The most important things I have learned working in a large Chinese lab are the values of hard work, collaboration and team work. Almost all of the work going on in Professor Gao's lab is very team orientated, which is a key factor in the success of most of the projects. For protein structure experiments, as an example, whether it's starting from protein 


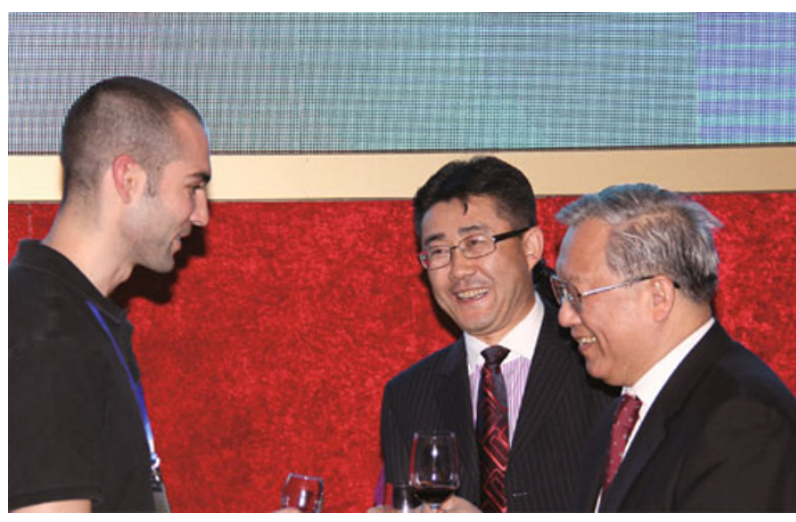

A toast with Yongxiang Lu, President of Chinese Academy of Sciences, and George Fu Gao, at the banquet for the IAC Workshop on Backyard Surveillance of Emerging Infectious Diseases in Beijing, China.

expression systems, purification, functional studies, crystallization, data collection and processing, and all the way to manuscript preparation, it is virtually impossible for a single individual to successfully complete all the necessary steps on their own. Even for the protein purification, functional analysis, and crystal screening process alone, in most cases this must be done against the clock, as many proteins are unstable and denature rather quickly. Therefore the ability to work in groups is extremely valuable for increasing the efficiency and success of many experiments. In science, practically all discoveries are based upon some knowledge that was discovered previously. Furthermore, the biggest discoveries are almost always based upon the efforts of many individuals over many years of time. On the large scale, it is extremely important that scientists all over the world can collaborate to provide new scientific breakthroughs that can improve the quality of human life. I sincerely hope that both the United States and China will continue to promote and support collaboration and exchange between our scientists to foster the advancement of science for people everywhere.

\section{ACKNOWLEDGEMENTS}

For the last 2 years Christopher Vavricka has been solely supported by the Chinese Academy of Sciences Fellowship for Young International Scientists (2010Y2SB12 and 2009Y2BS2) and National Natural Science Foundation of China Research Fund for International Young Scientists (Nos. 31150110147 and 31050110126 ).

\section{REFERENCES}

Li, Q., Qi, J., Zhang, W., Vavricka, C.J., Shi, Y., Wei, J., Feng, E., Shen, J., Chen, J., Liu, D., et al. (2010). The 2009 pandemic H1N1 neuraminidase $\mathrm{N} 1$ lacks the 150 -cavity in its active site. Nat Struct Mol Biol 17, 1266-1268.

Liu, J., Wu, P., Gao, F., Qi, J., Kawana-Tachikawa, A., Xie, J., Vavricka, C.J., Iwamoto, A., Li, T., and Gao, G.F. (2010). Novel immunodominant peptide presentation strategy: a featured HLA$A * 2402$-restricted cytotoxic T-lymphocyte epitope stabilized by intrachain hydrogen bonds from severe acute respiratory syndrome coronavirus nucleocapsid protein. J Virol 84, 11849-11857.

Vavricka, C., Han, Q., Huang, Y., Erickson, S.M., Harich, K., Christensen, B.M., and Li, J. (2011a). From L-dopa to dihydroxyphenylacetaldehyde: a toxic biochemical pathway plays a vital physiological function in insects. PLoS One 6, e16124.

Vavricka, C.J., Christensen, B.M., and Li, J. (2010a). Melanization in living organisms: a perspective of species evolution. Protein Cell 1 , 830-841.

Vavricka, C.J., Liu, Y., Li, Q., Shi, Y., Wu, Y., Sun, Y., Qi, J., and Gao, G.F. (2011b). Special features of the 2009 pandemic swine-origin influenza A H1N1 hemagglutinin and neuraminidase. Chin Sci Bull 56, 1747-1752.

Vavricka, C.J., Qi, J., Wu, Y., Qi, J., Wang, M., Liu, Y., Gao, F., Liu, J., Feng, E., He, J., et al. (2011c). Structural and functional analysis of laninamivir and its octanoate prodrug reveals group specific mechanisms for influenza NA inhibition. PLoS Pathog (In press).

Vavricka, C.J., Ray, K.W., Christensen, B.M., and Li, J. (2010b). Purification and $\mathrm{N}$-glycosylation analysis of melanoma antigen dopachrome tautomerase. Protein J 29, 204-212.

Wang, M., Qi, J., Liu, Y., Vavricka, C.J., Wu, Y., Li, Q., and Gao, G.F. (2011). Influenza a virus $n 5$ neuraminidase has an extended 150cavity. J Virol 85, 8431-8435. 